\title{
Carcinoma of the gall bladder presenting as a retrograde intussusception of the duodenum
}

\author{
N. S. Williams \\ F.R.C.S.
}

\author{
B. A. SHOREY \\ F.R.C.S.
}

\section{Department of Surgery, Bristol Royal Infirmary}

\begin{abstract}
Summary
A case of carcinoma of the gall bladder presenting as a retrograde intussusception of the duodenum is described. Although this is a rare presentation of the disease, adequate radiography and endoscopy will help to establish the diagnosis.
\end{abstract}

\section{Introduction}

Obstruction of the duodenum when it occurs is usually due to scarring from a peptic ulcer. Duodenal diverticula, diaphragmatic webs, annular pancreas, superior mesenteric artery or tumours are rarely causative factors. Carcinoma of the gall bladder causing duodenal obstruction is very unusual (Friedman, Mehler and Ginzburg, 1969). A case of this rare occurrence is discussed which presented with the signs and symptoms of a retrograde intussusception of the duodenum. This is the first recorded case presenting in this manner.

\section{Case report}

An 89-year-old woman was admitted as an emergency with a 3-week history of anorexia, vomiting and weight loss. She had suffered from attacks of right hypochondrial pain which had recently become more severe. On examination she was very fit for her age, but she was dehydrated, had abdominal distension and mild right hypochondrial tenderness. No masses were palpable. Her serum electrolytes confirmed hypochloraemic alkalosis. Plain X-rays were unremarkable. Rehydration was commenced and a limited barium meal showed hold up distal to the duodenal cap. A constant filling defect was noted which contained rings of barium typical of the 'onion rings' found with intussusception (Fig. 1). Endoscopy showed a concentric ring of mucosa projecting in from the second part of the duodenum. The gastroscope could be passed into the third part of the duodenum but on withdrawal a polypoid mass of mucosa was evident at the junction of the 1st and 2nd parts of the duodenum. It was concluded that this was due to either a neoplastic or inflammatory mass invaginating the duodenum.

At laparotomy the gall bladder was thickened and contained stones, it was adherent to the transverse

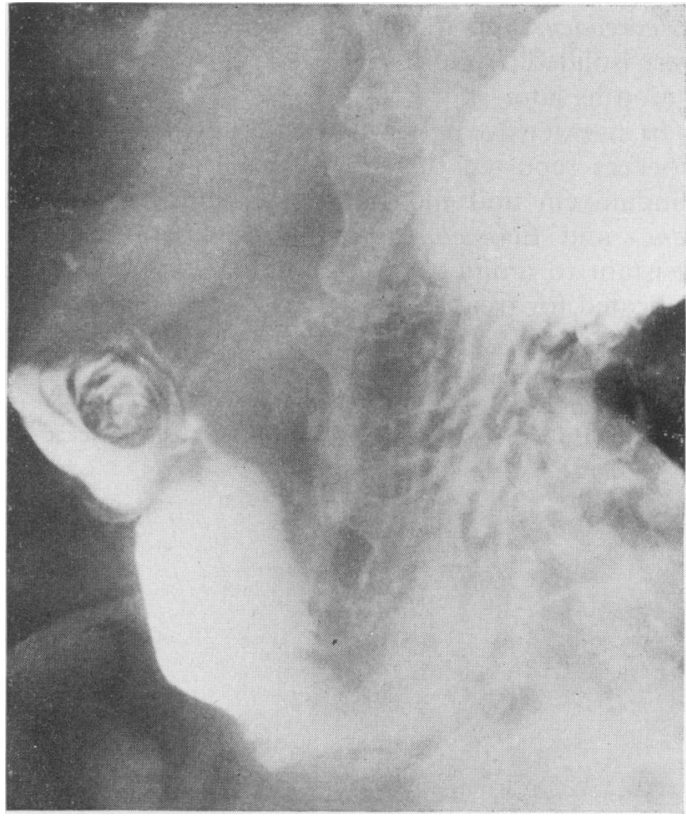

FIG. 1. Barium meal showing a constant filling defect in the first part of the duodenum, with the 'onion ring' appearance, indicative of an intussusception.

colon and was invaginating the 2nd part of the duodenum causing obstruction. A cholecystectomy was performed; general laparotomy elicited no further abnormality. Postoperatively the patient recovered well but developed bronchopneumonia and died on the 27th postoperative day. Histology showed a poorly differentiated carcinoma of the gall bladder.

\section{Discussion}

Carcinoma of the gall bladder is a rare tumour, accounting for less than $1 \%$ of all carcinomas in Britain (Solan and Jackson, 1971). It occurs about three times more commonly in females than in males (Gerst, 1961; Strauch, 1960; Hafstram, Zettergran and Akesson, 1973) and the majority of patients are above the age of 50 years (Lowe, 1972). Commonly 
the patients present with pain in the right hypochondrium, usually of long duration and suggestive of benign biliary tract disease. A mass is often palpable on abdominal examination, and jaundice, usually due to involvement of the extra-hepatic bile ducts, is seen in about $\mathbf{4 0 \%}$ of cases (Donaldson and Busuttil, 1975).

Less frequently the disease may present with evidence of peritoneal carcinomatosis and ascites (Adson, 1973) and occasionally it is an incidental finding either at laparotomy or post-mortem (Moosa et al., 1975). It is unusual for carcinoma of the gall bladder to cause gastro-intestinal obstruction. Cases of small bowel and colonic obstruction have been described (Donaldson and Busuttil, 1975; Prakash, Sharma and Pandit, 1975); however, the pyloroduodenal area is more commonly affected, although the incidence in most series is low (Hardy and Volk, 1971; Keil and De Weese, 1973; Prakash et al., 1975). This is well illustrated in a review of nearly 4000 cases of the disease by Vaittinen (1970), in which the incidence of duodenal obstruction was only $3.8 \%$. No case has yet been reported in the literature in which the tumour presented as a duodenal intussusception. Indeed the latter is so rare, that when radiological appearances suggest its occurrence, duodenal invagination by an extrinsic lesion should be suspected. In these circumstances, endoscopy is mandatory and the condition is then easily elucidated, as it was in this patient.

\section{Acknowledgment}

We would like to thank Dr Paul Salmon for his help with the endoscopy findings and Miss J. Masterman for secretarial assistance.

\section{References}

ADson, M.A. (1973) Carcinoma of the gall bladder. Clinics of North America, 53, 1203.

Donaldson, L.A. \& Busuttil, A. (1975) A clinico pathological review of 68 carcinomas of the gall bladder. British Journal of Surgery, 62, 26.

Friedman, J.H., Mehler, G. \& Ginzburg, L. (1969) Pyloroduodenal obstruction due to carcinoma of the gall bladder. American Journal of Gastroenterology, 52, 224.

Gerst, P.H. (1961) Primary carcinoma of the gall bladder. A 30 year summary. Annals of Surgery, 153, 369.

HARDY, M.A. \& VolK, H. (1971) Primary carcinoma of the gall bladder. A ten year review. American Journal of Surgery, 120, 800.

Hafstram, I., Zettergran, L. \& Akesson, L.A. (1973) The natural history of primary and secondary tumours of the liver. Acta chirurgica scandinavica, 139, 264.

KeIL, R.H. \& DE WeEse, M.S. (1973) Primary carcinoma of the gall bladder. American Journal of Surgery, 125, 726.

Lowe, W.C. (1972) Neoplasms of the Gastrointestinal Tract, 1st edn. Henry Kimpton Publications, London.

Moosa, A.R., Anagnost, M., Hall, A.W., Moraldi, A. \& SkinNer, D.B. (1975) The continuing challenge of gall bladder cancer. Survey of 30 years experience at the University of Chicago. American Journal of Surgery, 130, 57.

Prakash, A.T.M., Sharma, L.K. \& Pandit, P.N. (1975) Primary carcinoma of the gall bladder. British Journal of Surgery, 62, 33.

Solan, M.J. \& JACKson, B.T. (1971) Carcinoma of the gall bladder-a clinical appraisal and review of 57 cases. British Journal of Surgery, 58, 593.

Strauch, G.O. (1960) Primary carcinoma of the gall bladder. Surgery, 47, 368.

VAItTINEN, E. (1970) Carcinoma of the gall bladder. A study of 390 cases diagnosed in Finland 1963-1967. Annales chirugiae et gynaecologiae Fenniae, 168 (Suppl. 168), $1+$. 